\title{
Computer Aided Implementation of Estimator Based Inverse Dynamics Controller for the Control of Non-Measurable State Variables of an Autonomous Hybrid System
}

\author{
V. Shijoh, Member, IACSIT, M. V. Vaidyan, and M. V. Varghese
}

\begin{abstract}
A Computer aided implementation of an estimator based inverse dynamics controller (EBIDC) algorithm for the efficient control of the states, especially the non-measurable states of an autonomous hybrid system (AHS) is proposed in this paper. Case of a cylindrical three-tank hybrid system is demonstrated. The studies combining behaviors of both discrete event and continuous systems are of utmost importance nowadays and thus study of dynamics of hybrid systems and control strategies for performance improvement is very important in the present scenario. This algorithm makes use of a state estimator for estimating all the states of the system which uses a generic nonlinear model of the actual system. The efficacy of the developed EBIDC is demonstrated by conducting simulation studies using Matlab under different operating modes of the system. Both set point tracking and disturbance rejection capabilities of the proposed controller are also confirmed in this work. The robustness of EBIDC in controlling the non-measurable states is also analyzed under different uncertainties.
\end{abstract}

Index Terms-Autonomous hybrid systems, derivative-free state estimator, estimator based inverse dynamics controller, unscented kalman filter (UKF) in state estimation.

\section{INTRODUCTION}

Hybrid system is a very dynamic branch of engineering which deals with the systems of continuous, discrete time and discrete event behavior. In some of the earlier works reported, theories behind hybrid automata and the discrete control of continuous plant were considered [1], [2]. Later many approaches were reported in the literature in which the systems were considered to contain both continuous and discrete behavior and control of such systems were accomplished [3]-[16]. Subsequently studies like Lyapunov technique, applied for continuous nonlinear systems were extended to hybrid systems in [4]. Linear approximations of nonlinear systems were carried out in most of such studies as in [4] and [5]. In [6], with the help of constraint logic programming with interval arithmetic, a rigorous modeling, simulation and analysis approach for hybrid systems were proposed. A collection of modeling and classification of different benchmark hybrid systems are presented in [7]. However, direct use of nonlinear models for analysis and control of hybrid systems were reported in very few works

Manuscript received March 9, 2013; revised May 10, 2013.

V. Shijoh and M. V. Vaidyan are with the National Institute of Technology, Calicut, Kerala (e-mail: meshij4u@ gmail.com, mvv@ nitc.ac.in).

M. V. Varghese is with the Department of Computer Engineering, King Khalid University, Abha, KSA (e-mail: varghese86@gmail.com). and still it is a challenging area of research.

The potential of dynamic models of hybrid systems developed in state estimation along with the modeling was investigated in [10]-[14] and [16]. Recently, using Bayesian approach, a nonlinear model of hybrid system was proposed by combining multiple local linear models in [11].Using such model a novel state identification method and predictive control of the system were proposed for a class of hybrid systems. [12], [13] had recommended an ensemble Kalman filter (EnKF) based nonlinear model predictive control (NMPC) and UKF based fault tolerant control schemes for controlling the output variables of the AHS. In addition to UKF and EnKF based state identification, a method to identify noise covariance's associated with autonomous hybrid systems from the operating data was proposed in [14]. In that work, estimation of noise covariance matrices is formulated as a constrained optimization problem. Almost all the works reported in literature [11]-[14] were confined to estimation of state under normal operating conditions without uncertainties. The parameter and state estimation of an induction motor in different real-time operating conditions for model and plant were made in [15]. A generic nonlinear model describing the dynamics of an autonomous hybrid system was attempted in [16]. Also the design and performance analysis of a UKF based state estimator utilizing this generic nonlinear model was formulated for the three tank hybrid system under different uncertainties.

The state identification in [11] and [13]-[16] is based on UKF algorithm which was suggested by $\mathrm{S}$ J Julier and JK Uhlmann. This derivative-free state estimation algorithm for nonlinear system had been proposed in [17] to overcome the limitations of extended Kalman filter (EKF) based algorithm like Jacobian calculation with computational complexity. [18] explains the efficiency of UKF algorithm and its variant form square root UKF in detail.

From literature survey, it is found that no work with real time platform had been reported in the field of state estimation and control of non-measurable state variables of the AHS, under different real-time operating conditions. In this work, an EBIDC has been proposed for the efficient control of the non-measurable state variables of the AHS which is operating under different types of uncertainties. EBIDC consists of a UKF based state estimator part and a controller part as shown in Fig 2. Instead of directly measuring the states, these estimated state values are given as the feedback signal to the EBIDC, thereby leading to sensor less control. Simulation studies have been carried out to evaluate the effectiveness of EBIDC algorithm for controlling the non-measurable state variables of the three 
tank hybrid system under different operating conditions.

The organization of the paper is as follows. In Section II, Computer aided EBIDC implementation is described along with the nonlinear model development, state estimation algorithm and EBIDC control algorithm. Section III presents the simulation results and its analysis. Conclusion and scope for further studies are summarized in Section IV.

\section{EBIDC IMPLEMENTATION}

The generic nonlinear model of the three tank hybrid system is used for designing a nonlinear UKF based state estimator for estimating all the three states from the only one output variable $\left(h_{3}\right)$ as explained in [16]. In this work the estimated state variables are fed back to the inverse dynamics controller for controlling the non-measurable state variables. The EBIDC is implemented using a computer and Fig. 1 shows the schematic representation of the benchmark three-tank hybrid system along with the computer interfaces. The Fig. 2 shows the general block diagram of the proposed EBIDC. The constituents of EBIDC such as generic nonlinear prediction model, UKF algorithm and control law are described in the following subsections.

\section{A. Generic Nonlinear Prediction Model}

In the benchmark three tank hybrid systems shown in Fig. $1, h_{1}, h_{2}$ and $h_{3}$ are the continuous states and $z_{1}$ and $z_{2}$ in (1) are the discrete states. Fin 1 and $\mathrm{Fin}_{2}$ are the two inflow rates of water to the first and second tanks respectively. $Q_{i}$ represent flow rates of water through hand valves with corresponding valve coefficients $\mathrm{k}_{\mathrm{i}}$ and in [16] its equations are as (1).

$$
\begin{gathered}
\mathrm{Q}_{1}=\mathrm{k}_{1} \operatorname{sign}\left(\mathrm{h}_{1}-\mathrm{h}_{3}\right) \sqrt{2 \mathrm{~g}\left|\mathrm{~h}_{1}-\mathrm{h}_{3}\right|} \\
\mathrm{Q}_{2}=\mathrm{k}_{2} \operatorname{sign}\left(\mathrm{h}_{2}-\mathrm{h}_{3}\right) \sqrt{2 \mathrm{~g}\left|\mathrm{~h}_{2}-\mathrm{h}_{3}\right|} \\
\mathrm{Q}_{3}=\mathrm{z}_{1} \mathrm{k}_{3} \sqrt{2 \mathrm{~g}\left|\mathrm{a}\left(\mathrm{h}_{1}-\mathrm{h}_{0}\right)-\mathrm{b}\left(\mathrm{h}_{3}-\mathrm{h}_{0}\right)\right|} \\
\mathrm{Q}_{4}=\mathrm{z}_{2} \mathrm{k}_{4} \sqrt{2 \mathrm{~g}\left|\mathrm{c}\left(\mathrm{h}_{2}-\mathrm{h}_{0}\right)-\mathrm{b}\left(\mathrm{h}_{3}-\mathrm{h}_{0}\right)\right|} \\
\mathrm{Q}_{5}=\mathrm{k}_{5} \sqrt{2 \mathrm{~g}\left(\mathrm{~h}_{1}+\mathrm{h}_{\mathrm{d}_{1}}\right)} \\
\mathrm{Q}_{6}=\mathrm{k}_{6} \sqrt{2 \mathrm{~g}\left(\mathrm{~h}_{3}+\mathrm{h}_{\mathrm{z}}\right)} \\
\mathrm{Q}_{7}=\mathrm{k}_{7} \sqrt{2 \mathrm{~g}\left(\mathrm{~h}_{2}+\mathrm{h}_{\mathrm{d}_{2}}\right)}
\end{gathered}
$$

Here $\mathrm{a}, \mathrm{b}$ and $\mathrm{c}$ take the values 1 or 0 which shows that the water level in three tanks are above or below $\mathrm{h}_{0}$. Different parameters and valve discharge coefficients are tabulated in Table I and Table II respectively.

\begin{tabular}{lr}
\hline TABLE I: PARAMETERS RELATED TO THREE TANK HYBRID SYSTEM \\
\hline Parameter & Value \\
\hline Height of all Tanks & $0.60 \mathrm{~m}$ \\
Over flow height of all tanks & $0.55 \mathrm{~m}$ \\
Pump flow rating & $240 \mathrm{lph}$ \\
Pump input & $0-5 \mathrm{~V}$ \\
Inner diameter of all Tanks & $0.15 \mathrm{~m}$ \\
Inner diameter of all inter connecting pipes & $0.0125 \mathrm{~m}$ \\
\hline \hline
\end{tabular}

TABLE II: DISCHARGE COEFFICIENTS OF HAND VALVES

\begin{tabular}{cccc}
\hline \hline $\begin{array}{c}\text { Discharge } \\
\text { coefficient }\end{array}$ & Value $\left(\mathrm{m}^{2}\right)$ & $\begin{array}{c}\text { Discharge } \\
\text { coefficient }\end{array}$ & Value $\left(\mathrm{m}^{2}\right)$ \\
\hline $\mathrm{k}_{1}$ & $2.6363 \mathrm{E}-5$ & $\mathrm{k}_{4}$ & $3.4316 \mathrm{E}-5$ \\
$\mathrm{k}_{2}$ & $2.4891 \mathrm{E}-5$ & $\mathrm{~K}_{6}$ & $2.2538 \mathrm{E}-5$ \\
$\mathrm{k}_{3}$ & $3.7984 \mathrm{E}-5$ & $\mathrm{k}_{5}, \mathrm{k}_{7}$ & 0 \\
\hline \hline
\end{tabular}

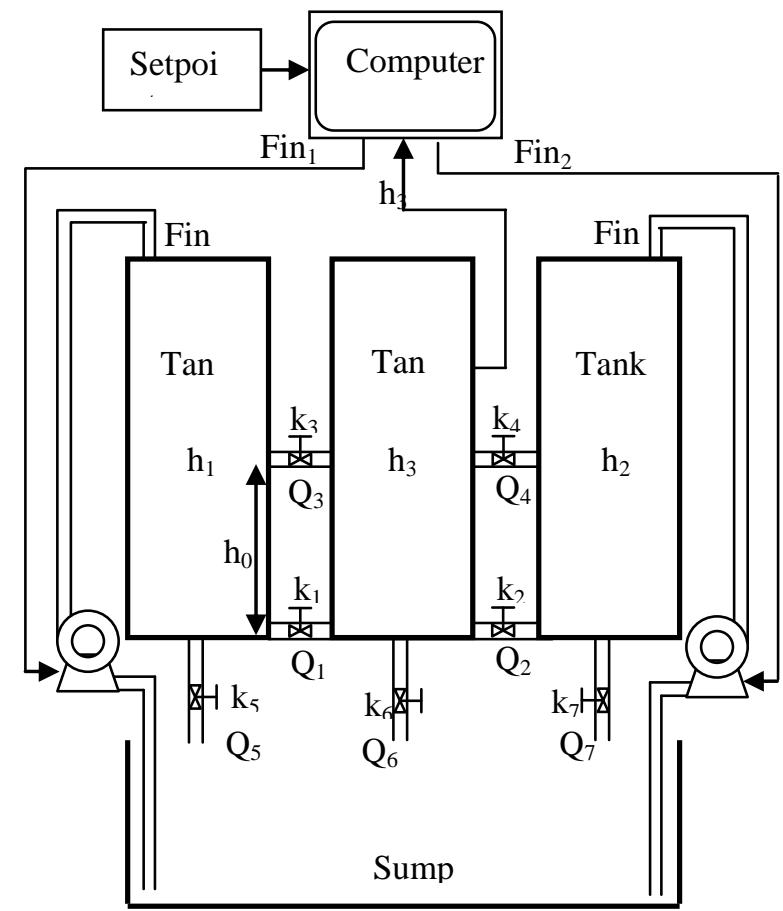

Fig.1. Schematic representation of autonomous three-tank hybrid system [16].

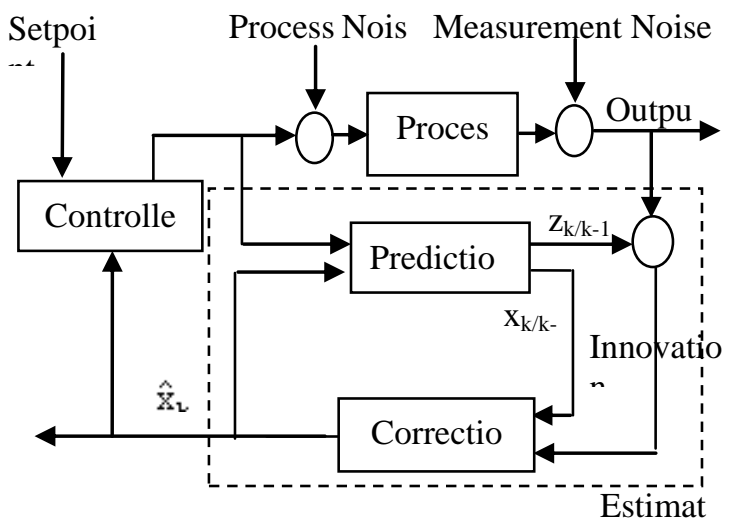

Fig. 2. General block diagram of EBIDC [16].

The generic nonlinear model of the system is given by (2), (3) and (4).

$$
\begin{aligned}
\frac{\mathrm{dh}_{1}}{\mathrm{dt}} & =\frac{1}{\mathrm{~A}_{1}}\left[\operatorname{Fin}_{1}-\mathrm{Q}_{1}-\mathrm{Q}_{3}-\mathrm{Q}_{5}\right] \\
\frac{\mathrm{dh}_{2}}{\mathrm{dt}} & =\frac{1}{\mathrm{~A}_{2}}\left[\operatorname{Fin}_{2}-\mathrm{Q}_{2}-\mathrm{Q}_{4}-\mathrm{Q}_{7}\right] \\
\frac{\mathrm{dh}_{3}}{\mathrm{dt}} & =\frac{1}{\mathrm{~A}_{3}}\left[\mathrm{Q}_{1}+\mathrm{Q}_{2}+\mathrm{Q}_{3}+\mathrm{Q}_{4}-\mathrm{Q}_{6}\right]
\end{aligned}
$$

where, $A_{1}, A_{2}$ and $A_{3}$ denotes the cross sectional area of three tanks

\section{B. State Estimation Algorithm [17]}

UKF based state estimation has been carried out to get the 
estimates of all the continuous state of the system. This method is very useful when the process contains high degree of nonlinearity where EKF based algorithms is not able to give optimum performance. The steps involved are as follows.

Step1: Assume the proper initial values for the states and state covariance $\left(\hat{\mathrm{x}}_{\mathrm{k}-1}\right.$ and $\left.\hat{\mathrm{P}}_{\mathrm{k}-1}\right)$.

Step2: Using these values, calculate the $2 n+1$ sigma points as given in (5).

$$
\begin{gathered}
\mathrm{x}_{\mathrm{k}-1}{ }^{(0)}=\hat{\mathrm{x}}_{\mathrm{k}-1} \\
\mathrm{x}_{\mathrm{k}-1}{ }^{(\mathrm{i})}=\hat{\mathrm{x}}_{\mathrm{k}-1} \pm \sqrt{(\mathrm{n}+\lambda) \hat{\mathrm{P}}_{\mathrm{k}-1}} \\
\lambda=\alpha^{2}(\mathrm{n}+\kappa)-\mathrm{n}
\end{gathered}
$$

where $i=1,2 \ldots 2 \mathrm{n}$ and ' $\mathrm{n}$ ' is the number of states.

The value of secondary scaling parameter $\kappa$ is selected as per the directions given in [18]. Tuning factor, $\alpha$ determines the spread of the sigma points around $\hat{\mathrm{X}}_{\mathrm{k}-1}$

Step3: Time update or prediction using the generic model is given in (6).

$$
\begin{gathered}
\mathrm{x}_{\mathrm{k} / \mathrm{k}-1}^{(\mathrm{i})}=\mathrm{F}\left(\hat{\mathrm{x}}_{\mathrm{k}-1}^{(\mathrm{i})}, \mathrm{u}_{\mathrm{k}}\right) \\
\mathrm{z}_{\mathrm{k} / \mathrm{k}-1}^{(\mathrm{i})}=\mathrm{H}\left[\mathrm{x}_{\mathrm{k} / \mathrm{k}-1}^{(\mathrm{i})}\right] \\
\mathrm{x}_{\mathrm{k} / \mathrm{k}-1}=\sum_{\mathrm{i}=0}^{2 \mathrm{n}} \mathrm{W}_{\mathrm{m}}^{(\mathrm{i})} \mathrm{x}_{\mathrm{k} / \mathrm{k}-1}^{(\mathrm{i})} \\
\mathrm{Z}_{\mathrm{k} / \mathrm{k}-1}=\sum_{\mathrm{i}=0}^{2 \mathrm{n}} \mathrm{W}_{\mathrm{m}}^{(\mathrm{i})} \mathrm{Z}_{\mathrm{k} / \mathrm{k}-1}^{(\mathrm{i})} \\
\mathrm{P}_{\mathrm{k} / \mathrm{k}-1}=\sum_{\mathrm{i}=0}^{2 n} \mathrm{~W}_{\mathrm{C}}^{(i)}\left[\mathrm{x}_{\mathrm{k} / \mathrm{k}-1}^{(\mathrm{i})}-\mathrm{X}_{\mathrm{k} / \mathrm{k}-1}\right]\left[\mathrm{x}_{\mathrm{k} / \mathrm{k}-1}^{(\mathrm{i})}-\mathrm{X}_{\mathrm{k} / \mathrm{k}-1}\right]^{\mathrm{T}}+\mathrm{Q}
\end{gathered}
$$

where $\mathrm{Q}$ is the process noise covariance whose value can be tuned to get optimum estimates and the associated weights $\mathrm{W}_{\mathrm{m}}$ and $\mathrm{W}_{\mathrm{c}}$ are computed as given in (7).

$$
\begin{gathered}
\mathrm{W}_{\mathrm{m}}{ }^{(\mathrm{i})}=\mathrm{W}_{\mathrm{C}}^{(\mathrm{i})}=\frac{1}{2(\mathrm{n}+\lambda)} \\
\mathrm{W}_{\mathrm{m}}^{(0)}=\lambda /(\mathrm{n}+\lambda) \\
\mathrm{W}_{\mathrm{C}}^{(0)}=\frac{\lambda}{(\mathrm{n}+\lambda)}+\left(1-\alpha^{2}+\beta\right)
\end{gathered}
$$

Here $\beta$ is the distribution factor which is used to include the knowledge of distribution of state. For Gaussian distribution, the optimum distribution factor is selected as 2 in [18].

Step4: Measurement update equations are given in (8).

$$
\begin{gathered}
\hat{\mathrm{P}}_{\mathrm{k}}=\mathrm{P}_{\mathrm{k} / \mathrm{k}-1}-\mathrm{K}_{\mathrm{k}} \mathrm{P}_{\mathrm{zz}} \mathrm{K}_{\mathrm{k}}^{\mathrm{T}} \\
\hat{\mathrm{X}}_{\mathrm{k}}=\mathrm{x}_{\mathrm{k} / \mathrm{k}-1}+\mathrm{K}_{\mathrm{k}}\left(\mathrm{z}_{\mathrm{k}}-\mathrm{Z}_{\mathrm{k} / \mathrm{k}-1}\right)
\end{gathered}
$$

where Kalman gain, $\mathrm{K}_{\mathrm{k}}=\mathrm{P}_{\mathrm{xz}} \mathrm{P}_{\mathrm{zz}}^{-1}$

$$
\begin{aligned}
& P_{z Z}=\sum_{i=0}^{2 n} W_{C}^{(i)}\left[\begin{array}{cc}
z^{(i)} & -z_{k / k-1}
\end{array}\right]\left[\begin{array}{cc}
z_{k / k-1}^{(i)} & -z_{k / k-1}
\end{array}\right]^{T}+R \\
& \mathrm{P}_{\mathrm{xz}}=\sum_{\mathrm{i}=0}^{2 n} \mathrm{~W}_{\mathrm{C}}{ }^{(\mathrm{i})}\left[\mathrm{x}_{\mathrm{k} / \mathrm{k}-1}^{(\mathrm{i})}-\mathrm{X}_{\mathrm{k} / \mathrm{k}-1}\right]\left[\mathrm{z}_{\mathrm{k} / \mathrm{k}-1}^{(\mathrm{i})}-\mathrm{z}_{\mathrm{k} / \mathrm{k}-1}\right]^{\mathrm{T}}
\end{aligned}
$$

Here $\mathrm{R}$ is the measurement error covariance which depends on the sensor used for measuring the output variable. $\mathrm{P}_{\mathrm{ZZ}}$ is the auto covariance of the output error and $\mathrm{P}_{\mathrm{XZ}}$ is the cross covariance of the state estimate error and output error.

\section{Control Law}

EBIDC has been proposed such that the dynamics of the controller is just inverse of the process dynamics. The inflow to Tank $1\left(\mathrm{Fin}_{1}\right)$ is considered as the manipulating variable for controlling the level in first tank $\left(\mathrm{h}_{1}\right)$ and the other inflow $\left(\mathrm{Fin}_{2}\right)$ can be manipulated to control the level in second tank $\left(h_{2}\right)$. The control law is given in (9).

$$
\begin{aligned}
& \mathrm{F}_{\mathrm{in}_{1}}=\mathrm{A}_{1} \mathrm{C}_{1}\left(\mathrm{~h}_{1 \mathrm{sp}}-\hat{\mathrm{h}}_{1}\right)+\mathrm{Q}_{1}+\mathrm{Q}_{3}+\mathrm{Q}_{5} \\
& \mathrm{~F}_{\mathrm{in}_{2}}=\mathrm{A}_{2} \mathrm{C}_{2}\left(\mathrm{~h}_{2 \mathrm{sp}}-\hat{\mathrm{h}}_{2}\right)+\mathrm{Q}_{2}+\mathrm{Q}_{4}+\mathrm{Q}_{7}
\end{aligned}
$$

Here $\mathrm{C}_{1}$ and $\mathrm{C}_{2}$ are the tuning parameters of the controller, $\mathrm{h}_{1 \mathrm{sp}}, \mathrm{h}_{2 \mathrm{sp}}$ are set points and $\hat{\mathrm{h}}_{1}, \hat{\mathrm{h}}_{2}$ are the estimated values for the levels in first and second tanks respectively.

\section{RESULTS AND ANALYSIS}
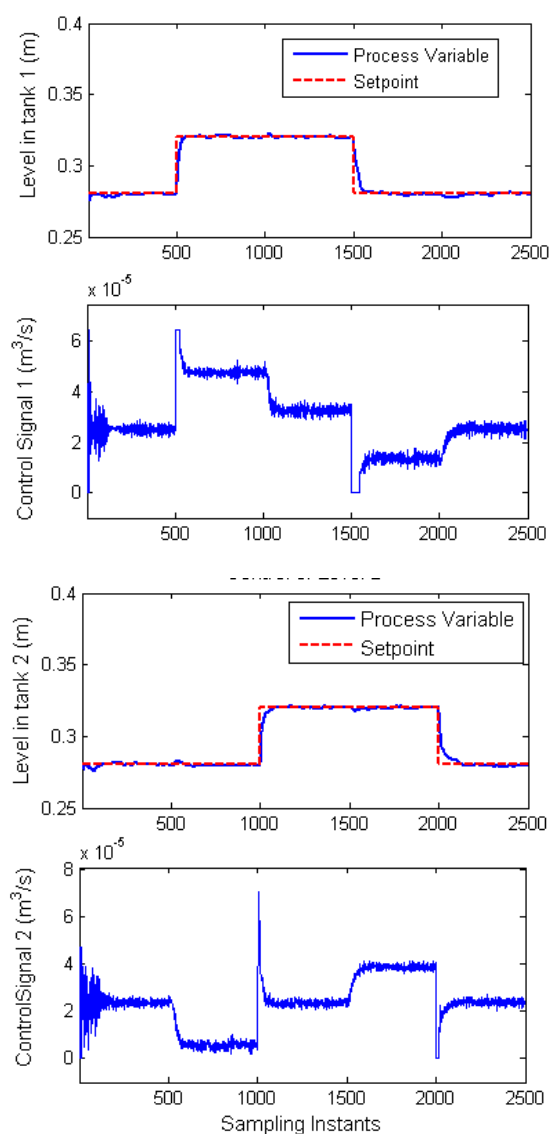

Fig. 3. Performance of the EBIDC when setpoint changes (Both controlled levels and controlling signals are shown for the levels h1 and h2). 

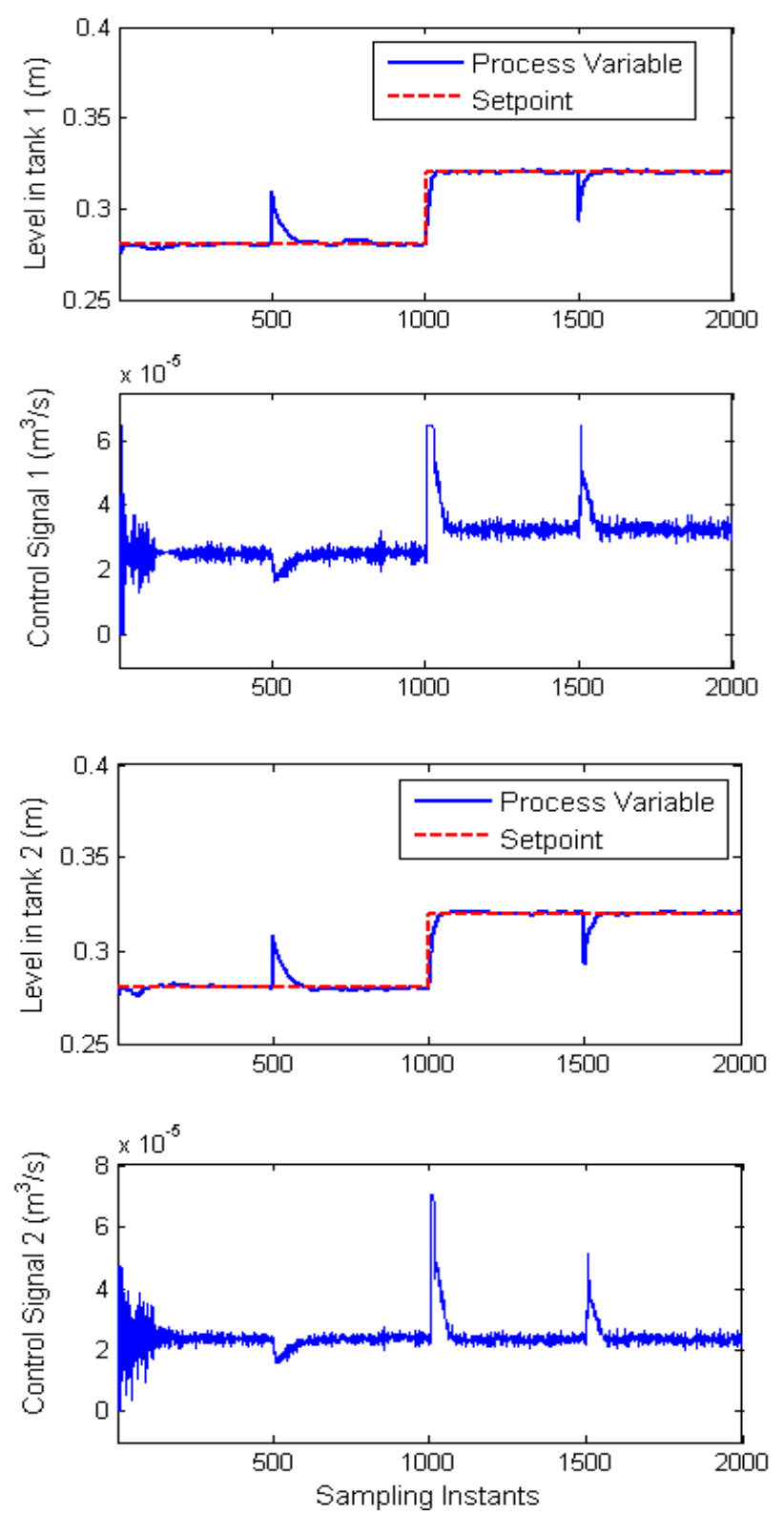

Fig. 4. Disturbance rejection at 500th and 1500th sampling instants (Both controlled levels and controlling signals are shown for the levels h1 and h2).



Fig. 5. Control of levels under mismatch of process and model parameter (mismatch factor $=1.1$ for Area and 1.05 for valve coefficients).

Before doing the detailed performance analysis of the proposed EBIDC, tuning of the controller has to be done by varying the tuning parameters of the controller, $\mathrm{C}_{1}$ and $\mathrm{C}_{2}$ to find the optimum controller settings. The performance of the controller is demonstrated when the levels are below and above the threshold value. Fig. 3 shows the simulation results of the EBIDC when servo operation is performed, from which it is clear that the controller designed has very good set point tracking capability.

In order to analyze the regulatory operation of the EBIDC, a disturbance is given externally to tank level by directly adding or removing some quantity of water at different sampling instants and the result shown in Fig. 4 reveals that the controller proposed has good disturbance rejection capability.


Fig. 6. Control of levels under initial condition mismatch.
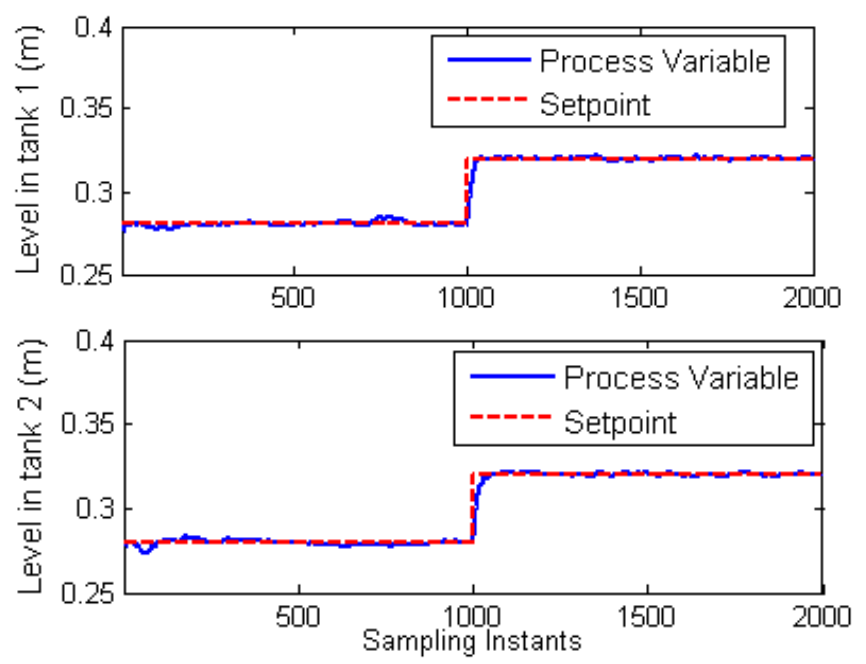

Fig. 7. Control of levels under higher noise level.

Fig. 5, Fig. 6 and Fig. 7 show the performance of the controller in controlling the levels $h_{1}$ and $h_{2}$ under different real time operating constraints such as process-model parameter mismatch, initial condition mismatch and variation in noise level, respectively. These results show that the proposed EBIDC is robust enough to manage with these uncertainties. It gives an offset under parameter mismatched condition and the value of offset increases when the mismatch in parameter especially valve coefficients increases. A quantitative study of the performance is made in terms of integral square error for the process model parameter mismatch condition which is tabulated in the Table III. From this analysis it is found that the ISE increases as the mismatch factor between the parameters of actual and model increases. 
Still the controller gives good control action if the model parameter lies within the $10 \%$ of actual value.

Since the levels in first and second tanks are not measurable, mismatches in initial values of these levels are introduced. The EBIDC is able to control the process variables at the desired set points within few sampling instants. Table IV gives the details of initial values of all the states of system and model.

TABLE III: ESTIMATOR PERFORMANCE MEASURE WITH AND WITHOUT MISMATCH OF PROCESS AND MODEL PARAMETERS

\begin{tabular}{ccc}
\hline \hline Parameter mismatch & $\mathrm{ISE}_{1}$ & $\mathrm{ISE}_{2}$ \\
\hline $\mathrm{A}_{\mathrm{m}}=\mathrm{A}_{\mathrm{p}}, \mathrm{k}_{\mathrm{m}}=\mathrm{k}_{\mathrm{p}}$ & 0.0138 & 0.0128 \\
$\mathrm{~A}_{\mathrm{m}}=1.1 \mathrm{~A}_{\mathrm{p}}, \mathrm{k}_{\mathrm{m}}=1.05 \mathrm{k}_{\mathrm{p}}$ & 0.0264 & 0.0162 \\
$\mathrm{~A}_{\mathrm{m}}=0.9 \mathrm{~A}_{\mathrm{p}}, \mathrm{k}_{\mathrm{m}}=0.95 \mathrm{k}_{\mathrm{p}}$ & 0.0324 & 0.0267 \\
$\mathrm{~A}_{\mathrm{m}}=1.5 \mathrm{~A}_{\mathrm{p}}, \mathrm{k}_{\mathrm{m}}=1.2 \mathrm{k}_{\mathrm{p}}$ & 0.1917 & 0.1890 \\
\hline \hline
\end{tabular}

TABLE IV: INITIAL VALUES OF ALL THE STATES OF SYSTEM AND MODEL

\begin{tabular}{cccc}
\hline \hline & $\mathbf{h}_{\mathbf{1}}(\mathbf{m})$ & $\mathbf{h}_{\mathbf{2}}(\mathbf{m})$ & $\mathbf{h}_{\mathbf{3}}(\mathbf{m})$ \\
\hline System & 0.28 & 0.28 & 0.23 \\
Model & 0 & 0 & 0.23 \\
\hline \hline
\end{tabular}

\section{CONCLUSION}

Computer aided implementation of EBIDC to control the non-measurable state variables of the three tank hybrid system has been demonstrated in this work. The results show that it has good servo and regulatory performance in controlling the nonmeasurable states under various uncertainties like parameter, initial state and noise level variations. Also it is noticed that the time taken to generate the control signal after obtaining the sensor output in each iteration is less than $0.3 \mathrm{~s}$ which is due to the time consumption for the estimation of states and still it is lesser than the sampling time considered for this process. Therefore computer aided online implementation is feasible in this case. For fast dynamic processes, the possibility of estimator based controller which makes use of EKF, Particle filter, ANN based filter etc. is to be investigated in future.

\section{REFERENCES}

[1] T. A. Henzinger. "The theory of hybrid automata," in Proc. Eleventh Annual IEEE Symposium on Logics in Computer Science, LICS'96, New Jersey, 27-30 July, pp. 278-292.

[2] J. M. Davoren and A. Nerode, "Logics for Hybrid Systems," in Proc. the IEEE, vol. 88, no. 7, July 2000, pp. 985-1010.

[3] B. De Schutter, "Optimal control of a class of linear hybrid systems with saturation," SIAM Journal on Control and Optimization, vol. 39, no. 3, pp. 835-851, 2000.

[4] M. Rubensson and B. Lennartson, "Stability of Limit Cycles in Hybrid Systems using Discrete-Time Lyapunov Techniques," in Proc. 39th IEEE Conference on Decision and Control, Sydney, Australia December, 2000, pp. 1397-1402.

[5] B. Potocnik, A. Bemporad, F. D. Torrisi, G. Music, and B. Zupancic, "Hybrid modelling and optimal control of a multiproduct batch plant," Control Engineering Practice, vol. 12, no. 9, pp. 1127-1137.

[6] T. J. Hickey and D. K. Wittenberg, "Rigorous Modeling of Hybrid Systems Using Interval Arithmetic Constraints," in Proc. 7th International Workshop, HSCC'04, Philadelphia, March 25-27, 2004, pp. 402-416.

[7] K. Tomas. Bestiarium of Hybrid Systems. Eternal draft. [Online]. Available:

http://www.cs.utwente.nl/krilaviciust/publications/bestiarium.pdf
[8] T. Krilavičius, "Hybrid Techniques for Hybrid Systems," PhD dissertation, University of Twente, Enschede, The Netherlands, September 6, 2006. ISBN: 90-365-2397-4.

[9] J. Lygeros, C. Tomlin, and S. Sastry, (December 28, 2008). "Hybrid Systems: Modeling, Analysis and Control," [Online]. Available: http://www-inst.cs.berkeley.edu/ ee291e/sp09/handouts/book.pdf.

[10] T. Alizadeh, K. Salahshoor, M. R. Jafari, A. Alizadeh, and M. Gholami, "On-line Identification of Hybrid Systems Using an Adaptive Growing and Pruning RBF Neural Network," in Proc. IEEE conference ETFA, 2007, pp. 257-264.

[11] N. N. Nandola and S. Bhartiya, "A multiple model approach for predictive control of nonlinear hybrid systems," Journal of Process Control, vol. 18, issue 2, pp. 131-148, February 2008.

[12] J. Prakash, S. C. Patwardhan, and S. L. Shah, "Control of an Autonomous Hybrid System Using a Nonlinear Model Predictive Controller," in Proc. 17th World Congress of International Federation of Automatic Control Seoul, Korea, July 6-11, pp. 12510-12515.

[13] J. Prakash, S. C. Patwardhan, and S. L. Shah, "Design and Implementation Fault Tolerant Model Predictive Control Scheme on a Simulated Model of Three-Tank Hybrid System," in Proc. IEEE Conference on Control and Fault Tolerant Systems, Nice, France, October 6-8, 2010, pp. 173-178.

[14] A. Bavdekar and S. C. Patwardhan, "Identification of Noise Covariances for State Estimation of Autonomous Hybrid Systems," in Proc. 18th IFAC World Congress, vol.18, part 1, Milano, Italy, August 28 - September 2, 2011. pp. 9097-9102.

[15] S. Kumar, J. Prakash, and P. Kanagasabapathy, "A critical evaluation and experimental verification of Extended Kalman Filter, Unscented Kalman Filter and Neural State Filter for state estimation of three phase induction motor," Applied Soft Computing, vol. 11, no. 3, pp. 3199-3208, 2011.

[16] V. Shijoh and M. V. Vaidyan, "Development of Generic Dynamic Nonlinear Model for Autonomous Hybrid System and Design of Inverse Dynamics Controller and Derivative Free State Estimator in Presence of Uncertainties," in Proc. IEEE international conference iMac4s 2013, Palai, Kerala, India, March 22-23.

[17] S. J. Julier, J. K. Uhlmann, and H. F. Durrant-Whyte, “A new approach for filtering nonlinear systems," in Proc. American Control Conference, Seattle, WA, 1995, pp. 1628-1632.

[18] R. van der Merwe and E. Wan. "The square-root unscented kalman filter for state and parameter estimation," in Proc. International Conference on Acoustics,Speech, and Signal Processing (ICASSP), Salt Lake City, Utah, 2001. pp. 3461-3464.



V. Shijoh was born on May 30th, 1981 at Kozhikode, India and currently he is a research scholar in the Department of Electrical Engineering, National Institute of Technology, Calicut, India. He received B.Tech in Electrical and Electronics Engineering from Calicut University, Kerala, India and M. E. in Instrumentation Engineering from MIT Campus, Anna University, Chennai, India. His research interests include Process modeling and control, State estimation, and advanced model based control strategies. He has published papers in national and international refereed journals and conferences. Mr. Shijoh is a member in the IACSIT and IAENG.

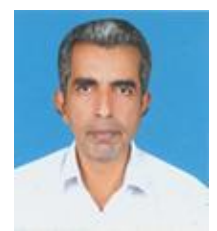

M. V. Vaidyan was born on January 10th, 1952 at Alleppey, Kerala. He has obtained bachelor of science (Engg) in 1972 and M.Sc (Engg) in 1975 from University of Kerala and PhD in 1996 from University of Calicut, India. Presently he is professor in Department Electrical Engineering, National Institute of Technology, Calicut, India. His research interest spans around system identification, embedded systems, computer controlled systems. model reference adaptive control systems, model predictive control, medical cybernetics, FPGA based system development etc.

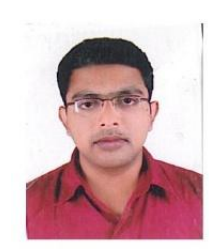

M. V. Varghese was born in 1986 at Kottayam, Kerala, India and currently is working with the Department of Computer Engineering, King Khalid University, Abha, KSA. He received B.Tech in Electrical and Electronics Engineering from University of Calicut, Kerala, India in 2007 and Masters degree in Electronics and Electrical Engineering from University of Glasgow Scotland in 2010. His research interests include Process control and control systems. 